\title{
EFFECT OF MELATONIN AND OMEPRAZOLE ON HEALING OF DUODENAL ULCER. HISTOLOGICAL AND IMMUNO- HISTOCHEMICAL STUDIES
}

\author{
By \\ Essam El-Mohandess*, Saad El-Shafey*, Fatma Ghonaim*, \\ and Talaat EL-Shehawy** \\ From \\ *Histology and Cytology Department, Faculty of Medicine, Mansoura University \\ ${ }^{* *}$ Gastro-Enterology Center Faculty of Medicine, \\ Mansoura University
}

\begin{abstract}
Background (Introduction): Melatonin has a widespread antioxidant activitiy that protects the gastrointestinal mucosa from oxidative damage and potentiates healing of duodenal ulcer. Omeprazole is also reported to be clearly effective in this healing process.
\end{abstract}

The aim of study: is to evaluate the role of melatonin and omeprazole in the treatment of duodenal ulcer either alone or in a combined therapy.

Subjects \& Methods: 36 adult male persons were included in this study. They were divided into 4 groups; group I (9 control volunteers), group II (9 patients suffering from chronic duodenal ulcer and receiving melatonin alone), group III (9 patients suffering from chronic duodenal ulcer and receiving omeprazole alone) \& group IV (9 patients suffering from chronic duodenal ulcer and receiving a combination of melatonin and omeprazole). Endoscopic biopsies were taken for histological \& immunohistochemical studies.

Results : Complete healing of the duodenal mucosa was observed after 8 weeks of treatment in Group II, after 6 weeks of treatment in Group III and after 4 weeks of treatment in Group IV. Before treatment, immuMANSOURA MEDICAL JOURNAL 
nohistochemical study of sections of ulcerated duodenum showed strong positive immune reaction for COX-2 enzyme. With treatment, the immune reaction was moderate then became mild or weak after complete healing.

Conclusion: it could be concluded that combination therapy of both melatonin and omeprazole is preferable in treatment of chronic duodenal ulcer as melatonin could accelerate the healing effect of omeprazole , shorten the duration of treatment and minimize its side effects.

Key Words: duodenum - ulcer melatonin - omeprazole - immunohistochemical - COX-2 enzyme.

\section{INTRODUCSTION}

Duodenal ulcer affects up to 1 to 10 people at some point in their lives, and tends to affect, specially, younger men. However, stomach ulcers are less common, rare in people before middle age and most common in elderly people ${ }^{1}$.

Duodenal ulcer may be acute (symptoms appear and improve quite quickly) or chronic (go on for a long time). Often several acute ulcers happen together, and these may produce no symptoms and heal without any long term consequences. Chronic ulcers are deeper, usually occur individually ,cause symptoms and leave a scar when they heal 2 .

The pineal secretory product, melatonin ( $\mathrm{N}$-acetyl -5- methoxytryptamine), is highly evolutionarily conserved molecule, present in virtually all organisms i.e. in both plants and animals. It has several important physiological functions in mammals including seasonal reproductive regulation, immune enhancement and regulation of light- dark signal transduction along with the capacity to influence possibly some aspects of aging. Additionally, it has been shown to have widespread antioxidant effects in variety of organs 3 .

Melatonin protects the gastrointestinal mucosa from oxidative damage caused by reactive oxygen species (ROS) in different experimental ulcer models. It reduces ethanol induced gastric damage and prevents gastric mucosal lesions caused by water -immersion restraint stress, ischemia and asprin 4 .

Melatonin protects against gastric 
ulceration in rats not only by scavenging $\mathrm{OH}$ radicals but also possibly by increasing the activities of two key gastric antioxidant enzymes, gastric peroxidase (GPO) and superoxide dismutase (SOD)4. It was stated that omeprazole is clearly effective in the healing of duodenal ulcer and in the resolution of the patient symptoms 5 .

Cyclo-oxygenase ( COX) is homodimer composed of two subunits of about 70,000 daltons and one heme group. Two isoforms of COX have been characterized; COX-1 and COX-2 6 . They are key enzymes involved in prostaglandin synthesis in human. COX-1 is constitutively expressed enzyme present in most cells and tissues throughout the body. It is responsible for generating prostaglandins involved in various physiological functions, including gastrointestinal mucosal protection. In contrast, COX-2 is rapidly induced at sites of inflammation and generates prostaglandins that mediate local inflammation and pain ${ }^{7}$.

In the normal stomach and duodenum of humans and animals, most studies found that COX-2 was expressed at low or undetectable lev- els and that its physiological role in normal stomach needs to be defined 8 .

The expression of COX-2 was increased in the ulcerated mucosa of the stomach and duodenum and its expression in the duodenal mucosa after ulceration is potent as in the gastric mucosa9. Its overexpression has been reported in several different pathological gastric conditions, including ulcer healing 10.

\section{Aim of work :}

The aim of this study is to evaluate the role of melatonin and omeprazole in the treatment of duodenal ulcer either alone or in combined therapy, and also to study the role of COX-2 in the healing process.

\section{SUBJECTS \& METHODS}

\section{A. Subjects}

A total of 36 subjects were included in this study. Twenty seven patients attending the outpatient clinics of The Gastro-Enterology Center, Mansoura University, were suffering from chronic duodenal ulcer. Nine healthy volunteers with age and sex matched were taken as controls. The age of both the control group and the duodenal ulcer patients ranged from 
32 to 64 years. All persons used in this study were subjected to upper gastrointestinal endoscopy for visualization of mucosal ulceration of the duodenum. An endoscopic biopsies were taken from all individuals in this study after taking their consents. Biopsies from patients were taken from the ulcer edges before and after treatment.

Patients selected were classified into 4 groups; group I included 9 healthy volunteers, the other 3 groups were subdivided into 3 subgroups each contained 3 patients:

1. Group I: Included 9 healthy volunteers used as control subjects.

2.Group II: Included 9 patients suffering from duodenal ulcers and receiving melatonin alone

in a dose of $3 \mathrm{mg}$ once daily for 4 weeks (Ila), 6 weeks (IIb) and 8 weeks (Ilc) 11

3. Group III: Included 9 patients suffering from duodenal ulcer and receiving omeprazole

alone in a dose of 40 mg once daily 4 weeks (IIla), 6 weeks (IIIb) and
8 weeks

(IIIc) 12 .

4. Group IV: Included 9 patients suffering from duodenal ulcer and receiving melatonin

and omeprazole in the same dose of each of them for 4 weeks (IVa), 6 weeks $\mathrm{Vb})$ and 8 weeks (IVc).

\section{B. Methods}

Biopsy samples were fixed in 10 $\%$ neutral buffered formalin for 24 hours. Dehydration was carried out in ascending grades of ethanol and xylol was used as a clearing agent then impregnation and embedding were done in paraplast. Serial sections were cut at 4-5 micrometer $(\mu \mathrm{m})$ in thickness and stained by :

1) Haematoxylin and Eosin 13 .

2) Periodic acid-Schiff's reaction (PAS) ${ }^{14}$.

3) Immunohistochemical (IHC) stain for localization of COX-2 enzyme by peroxidase Labeled Avidin-Biotin method $(\mathrm{LAB})^{15}$ using polyclonal rabbit anti-COX-2 .

Immunohistochemical stain for localization of Cox-2 enzyme: 
Kits used:

Primary antibody is a polyclonal rabbit anti-Cox2 (Cat $\neq$ RB-9072-R7. It is raised against a synthetic peptide derived from the $\mathrm{C}$-terminus of Cox2 from rabbit antiserum. It is reactive with rat, mouse and human Cox2. It is prepared at $1 \mathrm{mg} / 1 \mathrm{ml}$ in $10 \mathrm{mM}$ phosphate buffered saline (PBS). $\mathrm{pH} 7.6$, with $0.2 \%$ bovine serum albumin (BSA) and $15 \mathrm{mM}$ sodium azide. It is used for staining of formalin-fixed, paraffin-embedded tissues.

The detection kit used in this study was ultravision anti-polyvalent, HRP/ (Cat \# TP-015-HD) DAB, ready to use. The reagents in this kit constitute a labeled streptavidin-biotin immunoenzymatic antigen detection system. The reagents included in the detection system are hydrogen peroxided block, ultraviolet block, biotinylated goat anti-polyvalent (2ry antibody), streptavidin peroxidase, DAB substrate and DAB chromogen.

The kits used in this study were supplied by Lab Vision Corporation, UK.Ltd. They were stored at 2-8 ${ }^{\circ} \mathrm{C}$.

Steps of staining:

Paraffin sections were deparaffi- nized in xylene then rehydrated in descending grades of ethanol (100\%, 95\% and 70\%). Sections were not allowed to dry from this point on. Endogenous peroxidase activity was blocked by incubating the sections in hydrogen peroxide block for 10-15 minutes then washed 2 times in PBS. Excess buffer was blotted off. Antigen retrieval, for unmasking of antigens in formalinfixed, paraffin embedded sections, was done by boiling sections in citrate buffer $\mathrm{pH} 6.0$ for $10-20$ minutes followed by cooling at room temperature for 20 minutes then washed in PBS 4 times. Blocking of nonspecific background staining was done by applying ultraviolet block to the sections. Sections were then incubated for 5 minutes at room temperature. Time of incubation should not exceed 10 minutes or there may be a reduction in the desired stain. Excess serum was drained or blotted off without washing. Primary antibody, anti-Cox-2 (dilution 1:100), was applied to the sections. The slides were incubated in humidity chamber, at room temperature for 60 minutes.

Slides were then rinsed in PBS and dried around the edge of the

MANSOURA MEDICAL JOURNAL 
sections. Secondary antibody (the biotinylated goat anti polyvalent) was applied to the slides and incubated in the humidity chamber for $10 \mathrm{~min}$ utes at room temperature. The slides were rinsed in PBS and excess fluid was wiped off. Streptavidin peroxidase was applied to the section and the slides were incubated in the humidity chamber for 10 minutes at room temperature then rinsed in PBS and dried. The substratechromogen mixture was freshly prepared by adding 1-2 drops of $D A B$ chromogen to $1 \mathrm{ml}$ of $\mathrm{DAB}$ substrate and mix them by swirling. 2 drops or $100 \mu \mathrm{l}$ of this substrate chromogen mixture were applied to each section and the sections were incubated for 5-15 minutes.

Sections were rinsed well with distilled water, stained with Harris haematoxylin as counter stain, dehydrated in ascending grades of alcohol, cleared in xylene then mounted in Canada balsam and cover slipped. Brown cytoplasmic deposits at sites of specific cellular antigen indicated a positive reaction. Positive control sections (human cancer colon) were included within the working slides to assess the positivity of the tissue sections. Negative control sections were put under the same conditions after omitting the primary antibody. The negative control slide is important to assess the background staining.

\section{RESULTS}

Group I (Control volunteers):

In sections stained with $\mathrm{Hx} \& \mathrm{E}$, the epithelial lining of the human duodenum showed leaf-like projectinns into the lumen (villi) and tubular invaginations into the corium; the intestinal crypts of Lieberkuhn. The villi were covered with columnar absorbing cells ,having brush apical border, and goblet cells. The intestinal crypts of Lieberkuhn are simple tubular glands lined with simple columnar absorbing and goblet cells in their upper parts in addition to paneth and stem cells in their bases. The corium is formed of loose connective tissue containing some lymphocytic infiltrations, blood vessels and lymphatics in addition to the intestinal crypts. The muscularis mucosa is formed of a thin layer of smooth muscles separating the corium from the submucosa which appears as a layer of loose connective tissue containing Brunner's glands lined with mucous secreting columnar cells with foamy cytoplasm and flattened basal nuclei

Vol. 43, No. 1 \& 2 Jan. \& April, 2014 
(Fig.1). With PAS reaction, magenta color was typically demonstrated in the goblet cells, on the brush border of the absorping cells and in the acini of Brunner's glands (Fig.2).

In immunohistochemical staining, a section of human cancer colon was used as a control positive to demonstrate the strong positive immune reaction for COX-2 enzyme (Fig. 3). A negative control section was prepared from human duodenum after omitting the step of incubation with primary antibody ( Fig. 4). Immunohistochemical staining of the mucosa of the volunteer duodenum for COX2 enzyme revealed no expression in the cytoplasm of the epithelial cells covering the villi and lining the crypts (Fig. 5).

Before treatment (Ulcerated duodenum):

Sections of ulcerated duodenum, stained with $\mathrm{Hx}$ \& $\mathrm{E}$ showed shedding of a part of the mucosa including villi and crypts. At the site of the ulcer, there was a superficial layer of exudate (red amorphous substance) with entangling inflammatory cells (Figs. 6). Deeply, necrotic cells (with vacuolated cytoplasm \& pyknotic nucleus) and apoptotic cells (with deep- ly acidophilic cytoplasm \& pyknotic nucleus), were seen while in the floor of the ulcer, accumulation of mononuclear inflammatory cells were present. (Figs. 7). With PAS reaction, a positive reaction was seen in the goblet cells of some remaining crypts and in the acini of Brunner's glands. While, no villi were present. (Figs. 8)

Immunohistochemical staining of a section of ulcerated duodenal for COX-2 enzyme showed strong positive immune reaction in the cytoplasm of the inflammatory cells and epithelium of the crypts (Fig. 9).

After treatment: (healing ulcer)

A. Group II:

1. Group Ila (treated with melatonin for 4 weaks ):

Sections stained with Hx. \& E revealed partially regenerated parts showing granulation tissue that contains fibroblasts and congested capillaries without epithelial covering. On the other hand, completely regenerated areas showed that the granulation tissue developed into fibrous tissue covered with a single layer of epithelium (Fig. 10). The completely regenerated parts showed a positive PAS reaction in the brush border

MANSOURA MEDICAL JOURNAL 
of the surface epithelium while the incompletely regenerated parts showed a positive reaction in Brunner's glands under the raw surface (Fig. 11).

Immunohistochemical staining revealed strong positive immune reaction for COX-2 enzyme in the cytoplasm of the epithelium covering the healed parts as well as in the inflammatory cells in the corium of both the healed and ulcerated parts.

(Fig. 12).

\section{Group Ilb (treated with melat- onin for 6 weeks ):}

Hx. \& E stained sections showed progressive healing of the duodenal ulcer (Fig. 13). Regarding PAS reactions, it was strong positive in the brush border of the villous and crypt epithelium of the completely regenerated parts (Fig. 14).

There was a strong positive immune reaction for COX-2 enzyme in the cytoplasm of the surface epithelium and the inflammatory cells. (Fig. 15).

3. Group IIc (treated with melatonin for 8 weeks):

Sections stained with $H x$. \& $E$ showed complete healing of the duodenal mucosa. The amount of fibrous tissue increased and the epithelium formed a continuous layer (Fig. 16). PAS reaction was strong positive in the brush border of the epithelium covering the completely regenerated part (Fig. 17).

A mild immune reaction for COX2 enzyme was observed in the surface epithelium. (Fig. 18).

B. Group III:

1. Group IIla (treated with omeprazole for 4 weeks ):

There was an incomplete regeneration of the mucosa. Sections stained with Hx. \& E, , PAS and immunohistochemical reactions showed similar changes as in group Ilb. (Fig. 19,20,21)

\section{Group IIIb \& IIIc (treated with omeprazole for $6 \& 8$ weeks ).}

Complete healing of the duodenal mucosa was observed at the 6th week. Sections stained with Hx. \& E, PAS and immunohistochemical reactions showed similar changes as in group Ilc. (Fig. 22,23,24)
C. Group IVa, IVb \& IVc (treated with melatonin and omepra- 
Essam El-Mohandess et al...

zole for 4,6 \& 8 weeks ):

There was complete regeneration at the 4 th week. There were similar findings as in groups IIc and IIIb.

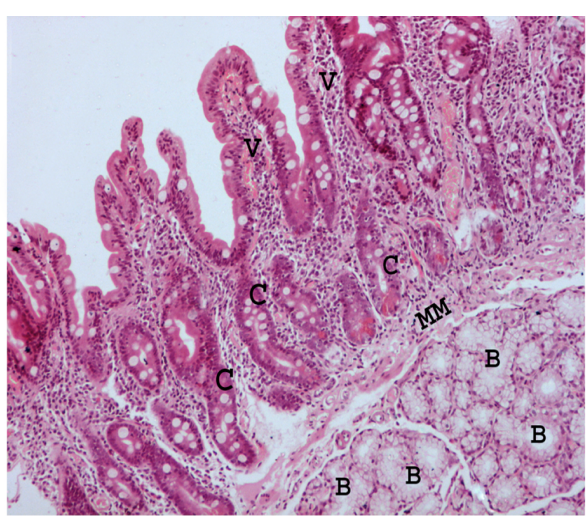

Fig 1: A photomicrograph of a section in the duodenum of a control volunteer (group I) showing duodenal villi (V) covered with columnar absorping and goblet cells, crypts (C) with paneth and stem cells at their bases, muscularis mucosa (MM) and submucosa containing Brunner's glands (B). $\quad$ (Hx \& E x 100).

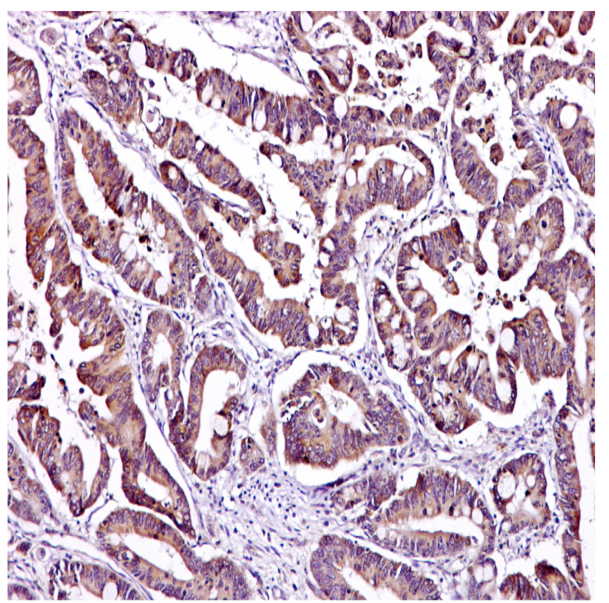

Fig 3 : A photomicrograph showing a strong immune-reaction for COX-2 enzyme in the cytoplasm of the lining epithelium of adenocarcinoma of the colon in the form of brown granules (positive control). IHC reaction for COX-2 enzyme x 250
The immune reaction for COX-2 enzyme was weak in the surface epithelium as compared with groups IIC and IIIb. (Fig. 25,26,27)

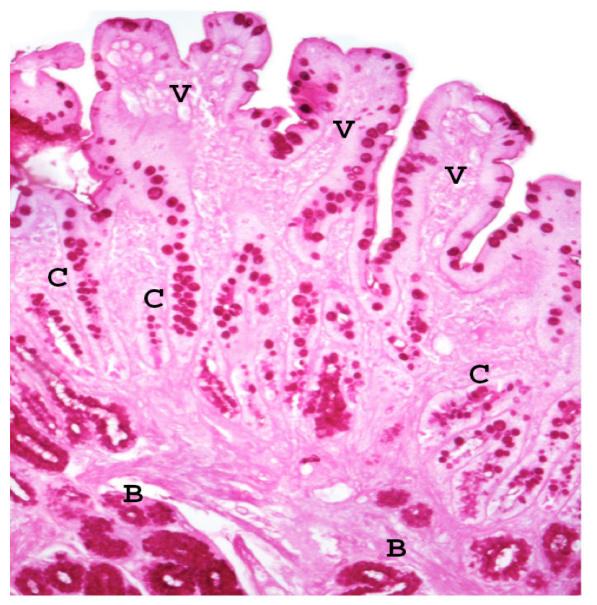

Fig 2: A photomicrograph of a section in the duodenum of a control volunteer (group I) showing magenta coloured goblet cells in the duodenal villi (V), crypts (C) and acini of Brunner's glands (B). (PAS x 250).

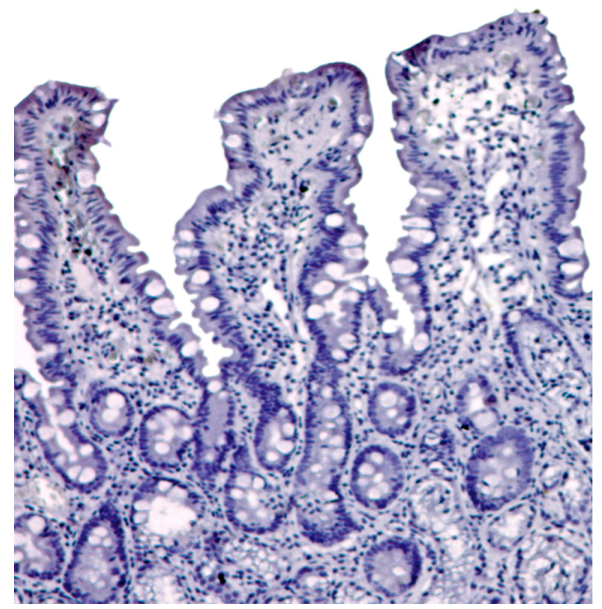

Fig 4: A photomicrograph showing a negative immune-reaction of COX-2 in the cytoplasm of the lining epithelium of the human duodenum (negative control). IHC reaction for COX-2 enzyme x 250 .

MANSOURA MEDICAL JOURNAL 


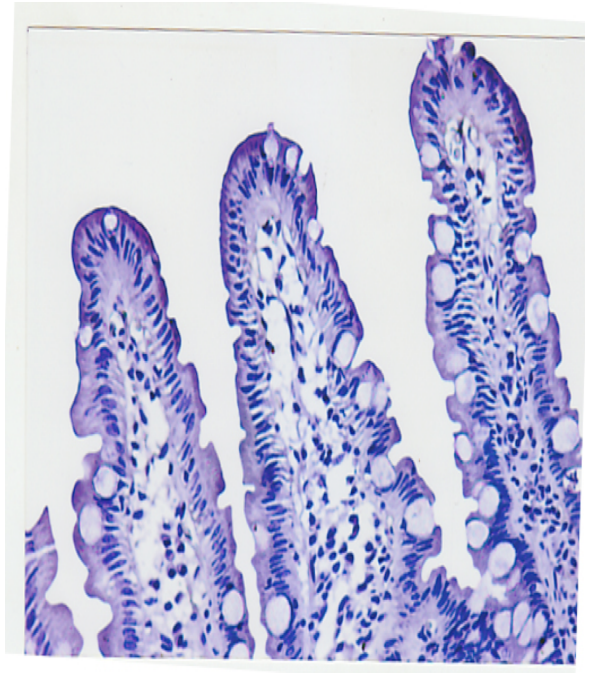

Fig 5 : A photomicrograph of a section in the duodenum of control volunteer (GroupI) showing a negative immune-reaction for COX-2 enzyme in the cytoplasm of the lining epithelium of the duodenum.

IHC reaction for COX-2 enzyme x 400

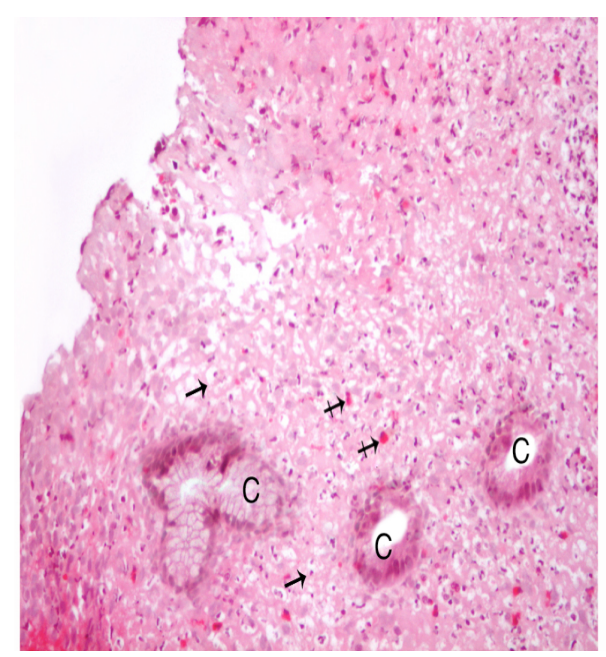

Fig 7 : A photomicrograph of a section in the duodenum of a patient with chronic duodenal ulcer showing necrotic cells (arrows) and apoptotic cells (crossed arrows) at the deep zone of the ulcer. Note the presence of some crypts $(\mathrm{C})$. (Hx \& E x 100)

Vol. 43, No. 1 \& 2 Jan. \& April, 2014

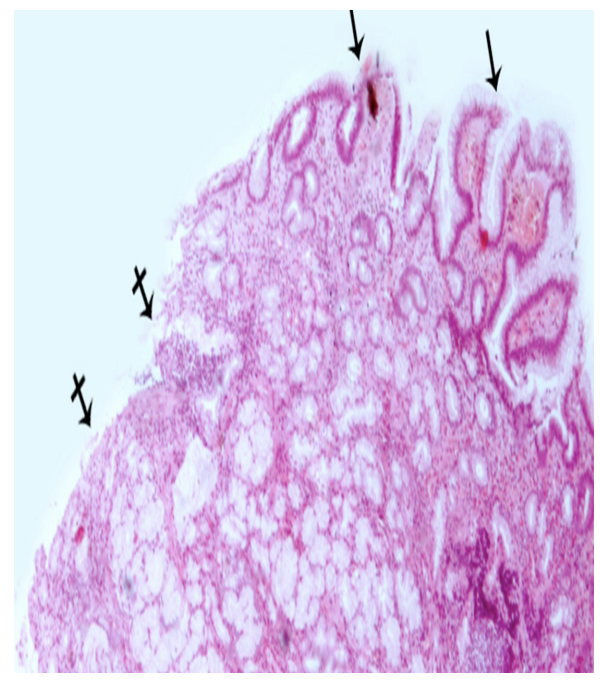

Fig 6: A photomicrograph of a section in the duodenum of a patient with chronic duodenal ulcer showing shedding of mucosa (crossed arrows), superficial layer of exudates (arrows) and lymphocytic infiltration (arrow head). ( Hx \& E x 100).

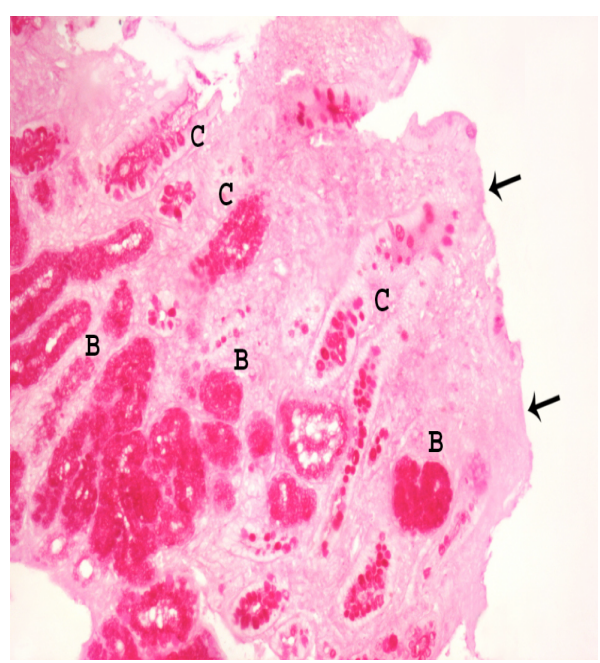

Fig 8: A photomicrograph of a section in the duodenum of a patient with chronic duodenal ulcer showing the ulcer site with absence of villi (arrows), small crypts (C) with magenta coloured goblet cells in addition to acini of Brunner's glands (B).
(PAS x 250). 


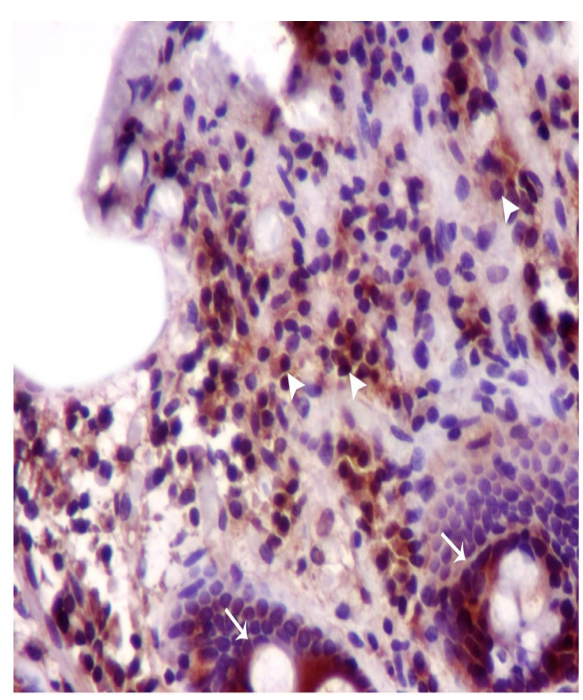

Fig 9 : A photomicrograph of a section in the duodenum of a patient with chronic duodenal ulcer showing a strong immune-reaction for COX-2 enzyme in the cytoplasm of inflammatory cells (arrow heads) and epithelial cells of the crypts (arrows). (IHC reaction for COX-2 enzyme x 400).

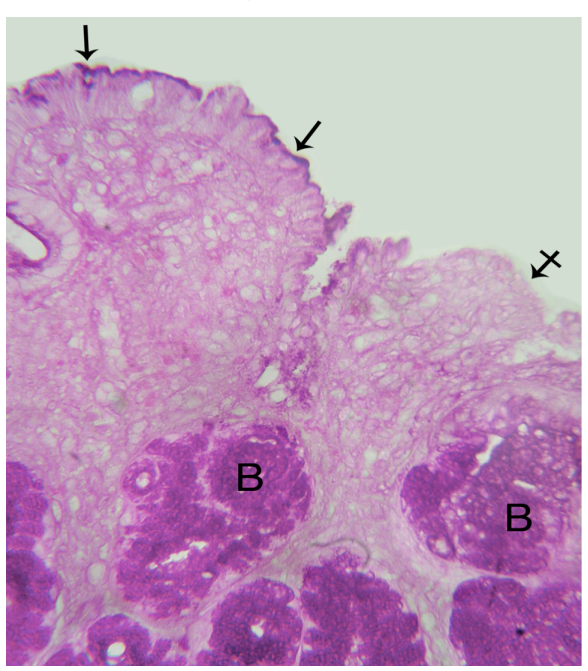

Fig 11 : A photomicrograph of a section in the duodenum of a patient with chronic duodenal
ulcer treated with melatonin for 4 weeks (Grouplla) showing regenerated parts of the surface epithelium with magenta colored regenerated (crossed arrows). Notice Brunner's glands (B) in the submucosa (PAS $x$ 250).

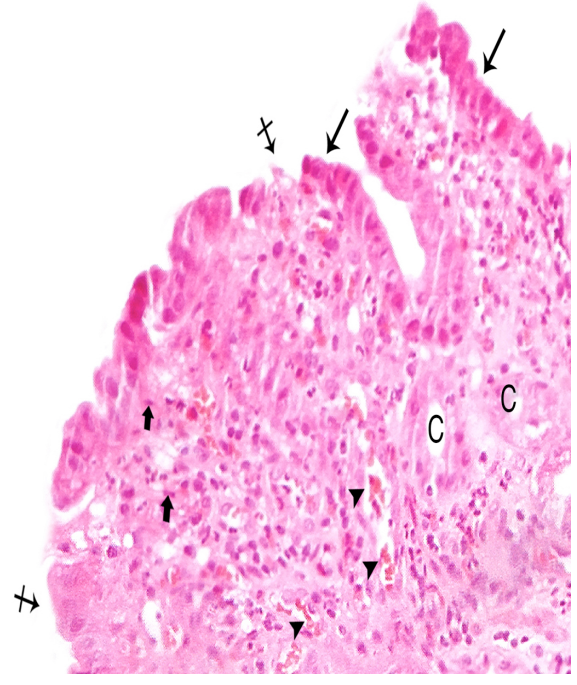

Fig 10: A photomicrograph of a section in the duodenum of a patient with chronic duodenal ulcer (rroupla) showing regenerated parts of the (Grouplace epithelium (arrows) and parts of the are not regenerated (crossed arrows) Fibroblasts (thick arrows and congested vessels (arrow heads) in addition to some crypts (C) are seen.

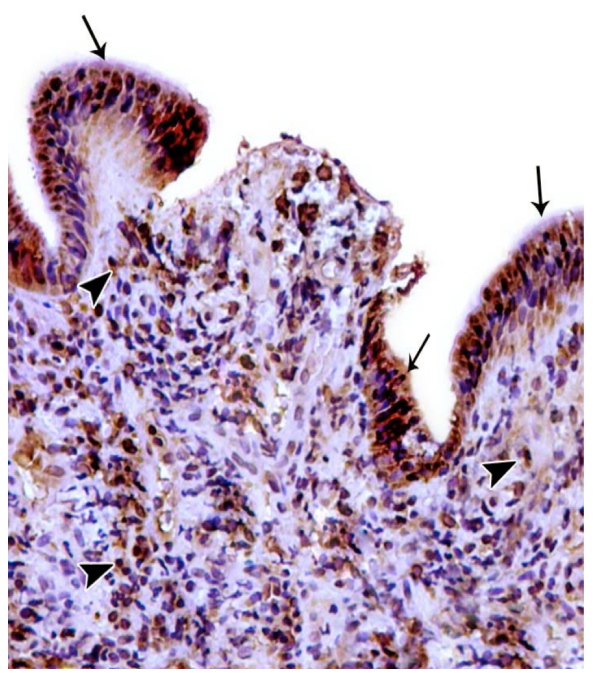

Fig 12: A photomicrograph of a section in the duodenum of a patient with chronic duodenal ulcer treated with melatonin for 4 weeks (GroupIIa) showing strong immune-reaction for COX-2 enzyme in the cytoplasm of the surface epithelium (arrows) and the inflamsurface epithelium (arrows) and the inflam-
matory cells (arrow heads). (IHC reaction for COX-2 x 250).

MANSOURA MEDICAL JOURNAL 


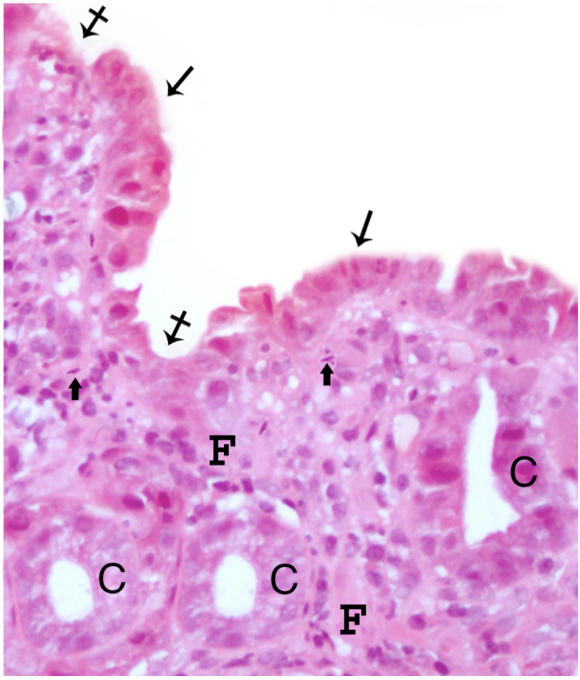

Fig 13 : A photomicrograph of a section in the duodenum of a patient with chronic duodenal ulcer treated with melatonin for 6 weeks (GroupIIb) showing regenerated parts (arrows) while other parts are incompletely regenerated (crossed arrows). Fibrous tisuue (F), fibroblasts (thick arrows) and some crypts (C) are seen. ( Hx \&E x 400).

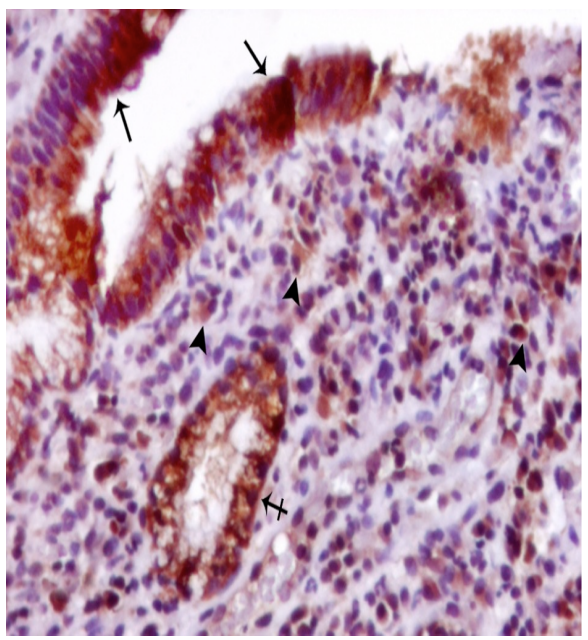

Fig 15 : A photomicrograph of a paraffin section of the duodenum a patient with chronic duodenal ulcer treated with melatonin for 6 weeks (Groupllb) showing strong positive immune reaction for COX-2 enzyme in the cytoplasm of the surface epithelium (arrows), in the crypts (crossed arrows) and in the inflammatory cells (arrow heads). (IHC reaction for COX -2 x 250).

Vol. 43, No. 1 \& 2 Jan. \& April, 2014

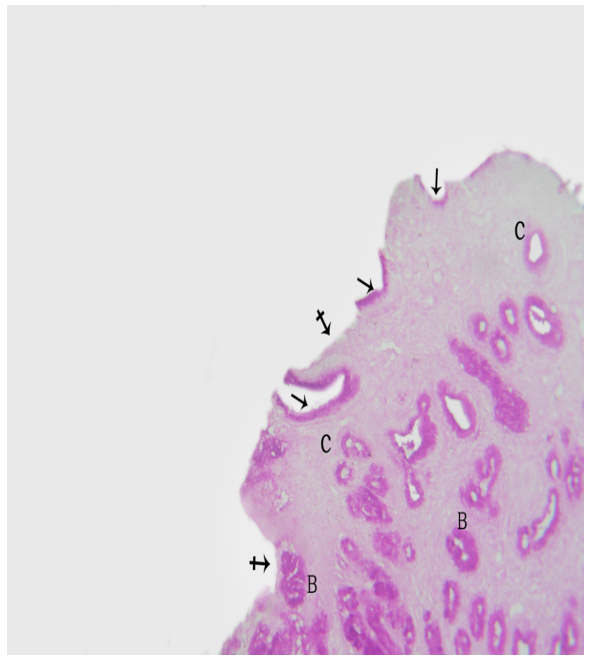

Fig 14: A photomicrograph of a paraffin section in the duodenum of a patient with chronic duodenal ulcer treated with melatonin for 6 weeks (Groupllb) showing regenerated parts of the surface epithelium with magenta colored brush border (arrows) and other parts are not regenerated (crossed arrows). Note presence of some crypts in the corium (C) and Brun-
ner's glands (B) in the submucosa. ( PAS X 100).

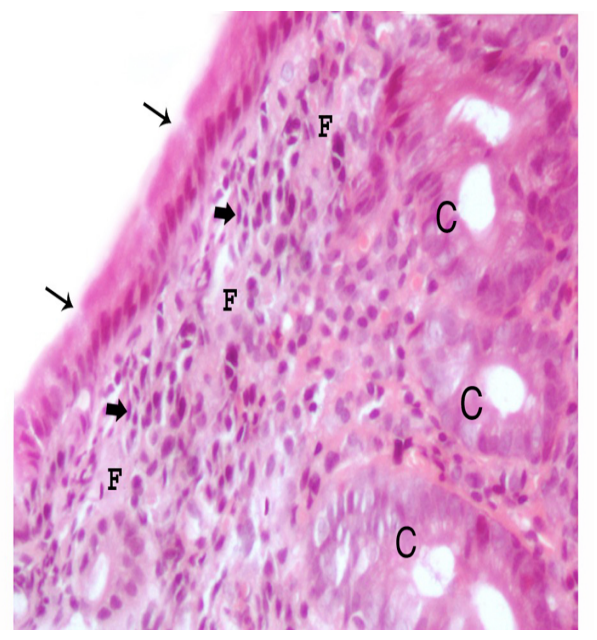

Fig 16 : A photomicrograph of a section in the duodenum of a patient with chronic duodenal ulcer treated with melatonin for 8 weeks (GroupIIc) showing complete regeneration of the surface epithelim (arrows) \& crypts (C). Note the increased amount of fibrous tisuue (F), fibroblasts (thick arrows). ( $\mathrm{Hx} \& \mathrm{E} x$ 400). 


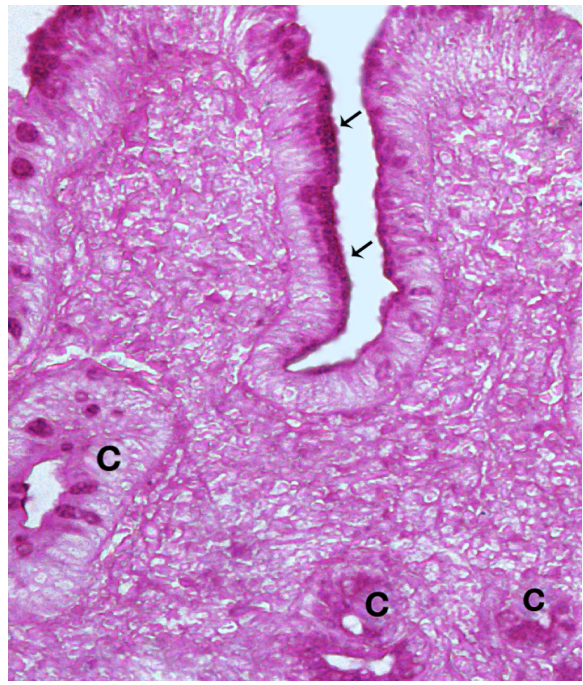

Fig 17 : A photomicrograph of a section in the duodenum of a patient with chronic duodenal ulcer treated with melatonin for 8 weeks (GroupIIc) showing complete regeneration of the surface epithelium (arrows) with magenta colored brush border and crypts (C). ( PAS x 400).

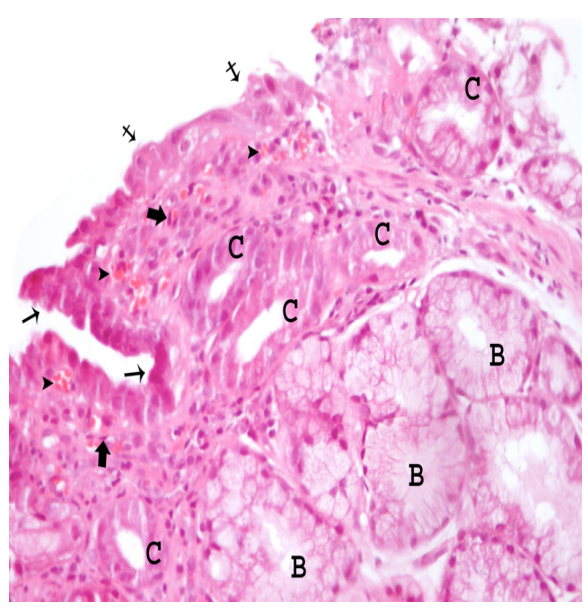

Fig 19 : : A photomicrograph of a paraffin section of the duodenum of a patient with chronic duodenal ulcer treated with omeprazole for four weeks (GroupIIIa): compare versus fig 13 ( Hx \& E x 250).

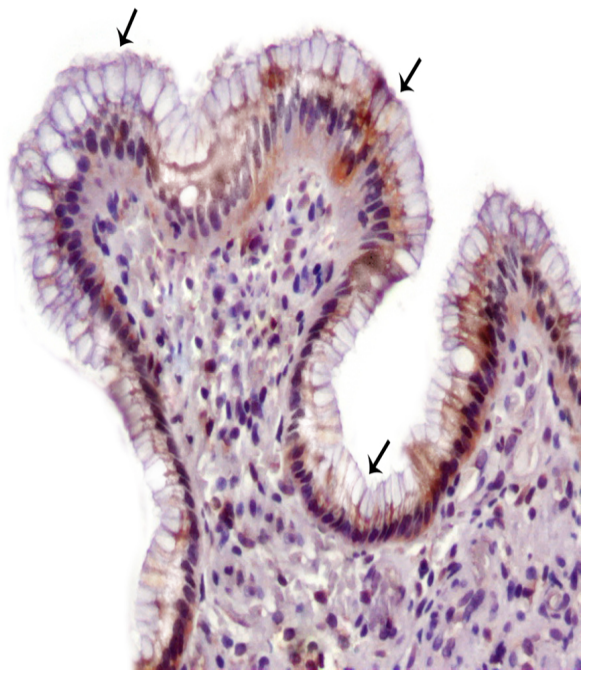

Fig 18: A photomicrograph of a section in the duodenum of a patient with chronic duodenal ulcer treated with melatonin for 8 weeks (GroupIIc) showing strong immune-reaction for COX-2 enzyme in the cytoplasm of the surface epithelium (arrows), the inflammatory cells (arrow heads). (IHC reaction for COX-2 x 250).

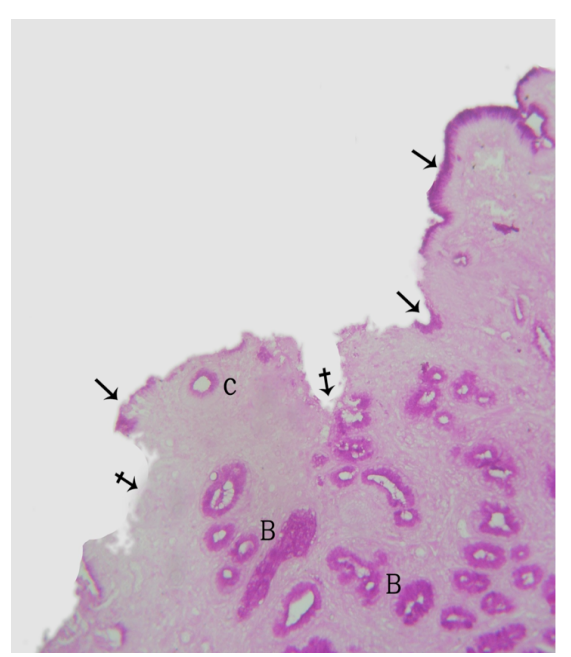

Fig 20 : A photomicrograph of a paraffin section of the duodenum of a patient with chronic duodenal ulcer treated with omeprazole for four weeks (GroupIIIa) : compare versus fig 14 (PAS x 100).

MANSOURA MEDICAL JOURNAL 


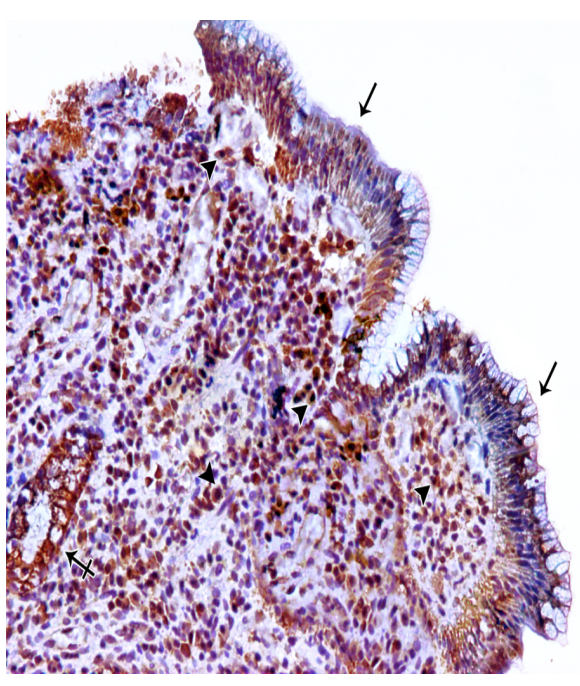

Fig 21 : A photomicrograph of a paraffin section of the duodenum of a patient with chronic duodenal ulcer treated with omeprazole for four weeks (GroupIIIa) : compare versus fig 15 (IHC reaction for COX-2 x 250).

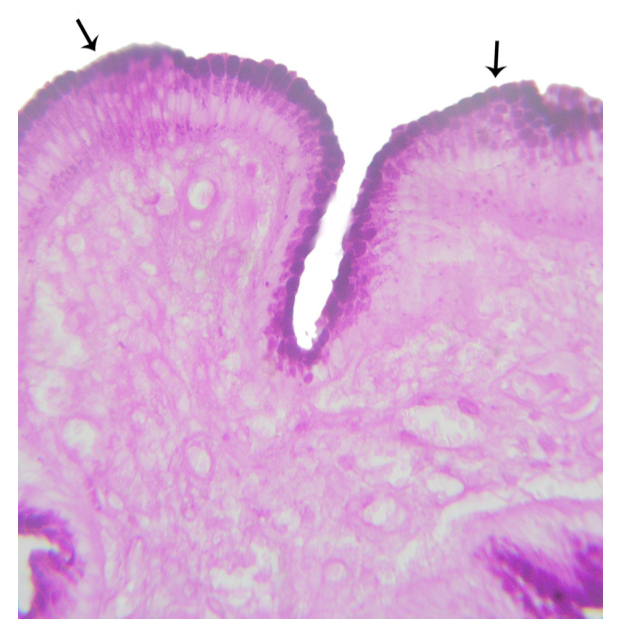

Fig 23 : : A photomicrograph of a paraffin section of the duodenum of a patient with chronic duodenal ulcer treated with omeprazole for six weeks (GroupIIIb): compare versus fig 17 ( PAS x 400).

Vol. 43, No. 1 \& 2 Jan. \& April, 2014

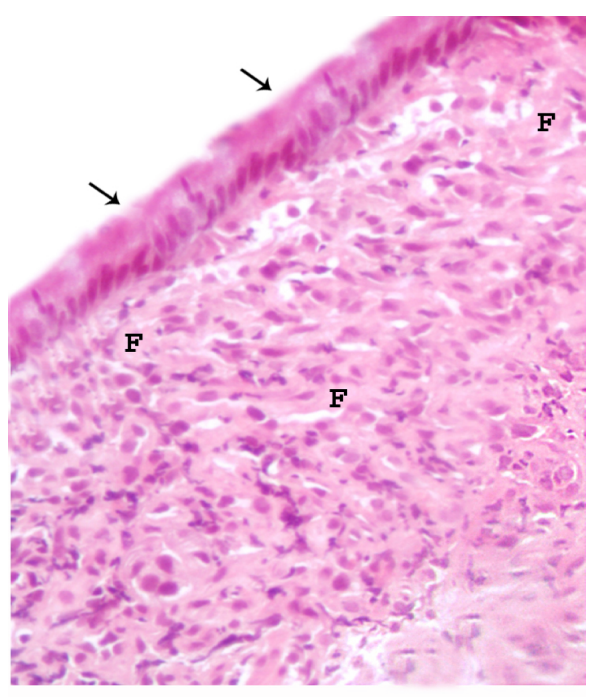

Fig 22: A photomicrograph of a paraffin section of the duodenum of a patient with chronic duodenal ulcer treated with omeprazole for six weeks (GroupIIIb): compare versus fig 16 ( Hx \& E x 400).

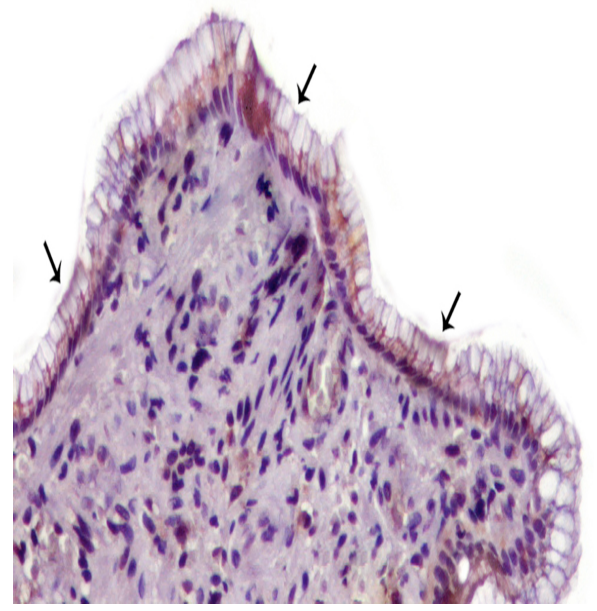

Fig 24 : A photomicrograph of a section in the duodenum of a patient with chronic duodenal ulcer treated with omeprazole for six weeks (GroupIIIb): compare versus fig 18 (IHC reaction for COX-2 x 250). 


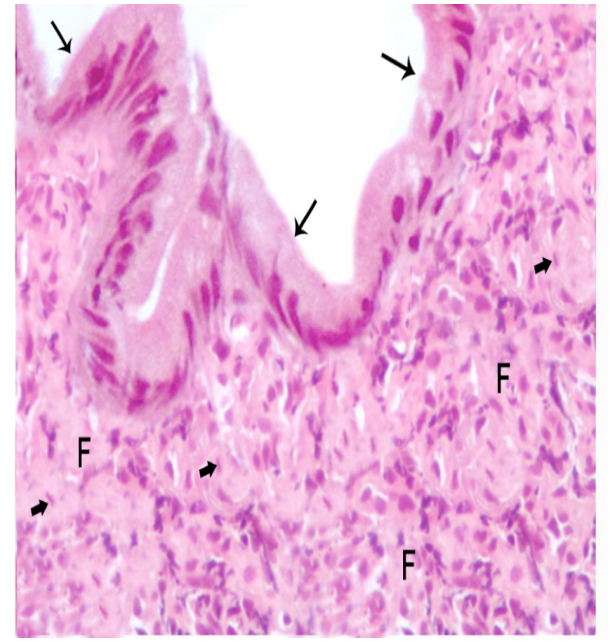

Fig 25 : A photomicrograph of a paraffin section of the duodenum a patient with chronic duodenal ulcer treated with melatonin and omeprazole for four weeks (GroupIVa): compare versus fig 16 ( $\mathrm{Hx} \& \mathrm{Ex} 400)$.

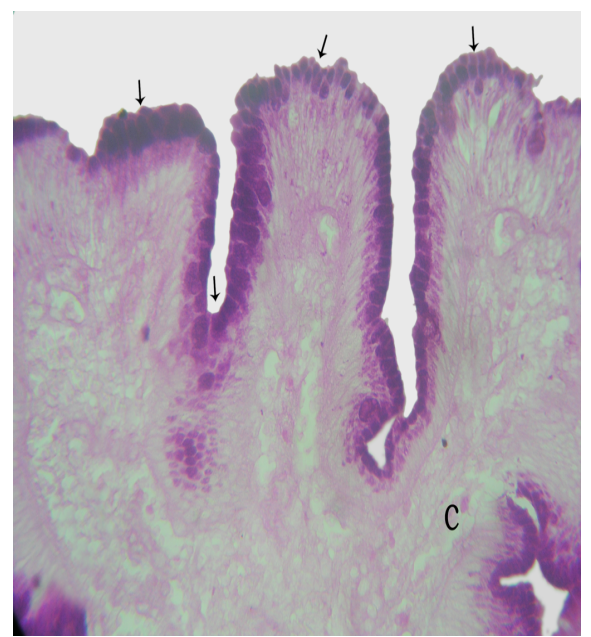

Fig 26: A photomicrograph of a paraffin section of the duodenum of a patient with chronic duodenal ulcer treated with melatonin and omeprazole for four weeks (GroupIVa) : compare versus fig $17 \quad$ ( PAS x 400)

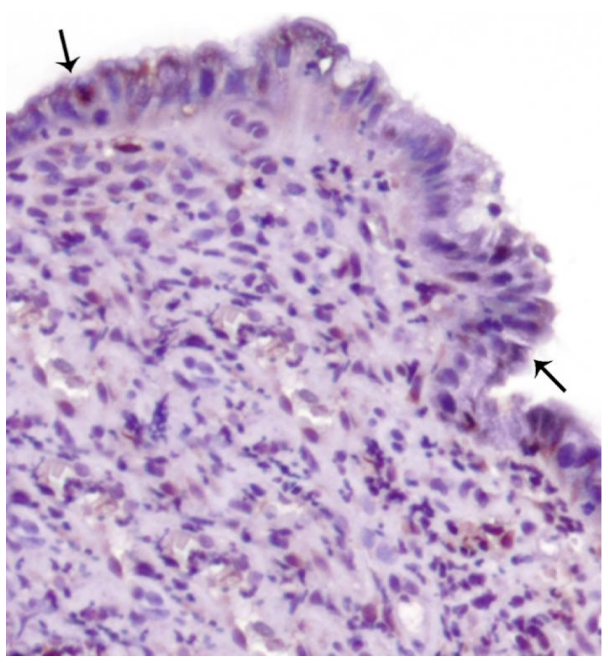

Fig 27 : A photomicrograph of a paraffin section of the duodenum of a patient with chronic duodenal ulcer treated with melatonin and omeprazole for four weeks (GroupIVa): compare versus fig 18 (IHC reaction for COX-2 x 400).

MANSOURA MEDICAL JOURNAL 


\section{DISCUSSION}

The current study evaluateed the histological effect of the recently used drug ,melatonin, and the widely used drug ,omeprazole, on treatment of duodenal ulcer. Moreover, immunohistochemical study of COX-2 was performed to clarify its possible role in the healing process.

The mucosa of the duodenum of the control volunteers consisted of epithelium covering the intestinal villi and lining the intestinal crypts, corium and muscularis mucosa. The intestinal epithelium covering the villi and crypts contained columnar absorptive cells with basal oval nuclei and goblet cells. The submucosa contained Brunner's glands. This finding was in agreement with ${ }^{16,17}$.

The results of the present study revealed that COX-2 was not expressed in the normal duodenal mucosa of the healthy control group. This coincides with18 who stated that COX-2 is inducible and not constitutively expressed like COX-1, and that COX-2 protein is absent from normal duodenal tissues.

Microscopic examination of the ulcerated duodenum revealed a thin layer of exudate containing acute inflammatory cells, a layer of necrotic tissue appearing as an amorphous eosinophilic layer containing necrotic cells and apoptotic cells and mononuclear inflammatory cells at the base of the ulcer. These findings could be explained by increasing COX-2 enzyme ,as a result of tissue damage, leading to production of prostaglandine that modulated such inflammatory and immune response. In the present work, no prominent histological variations were found between the ulcers of different individuals.

In the untreated ulcer, there was an increased expression of COX-2 and this was confirmed by 19 who mentioned that COX2 expression occurs in certain cell types by proinfalmmatory or mitogenic agents, including cytokines, endotoxins and tumour promotors as well as by growth factors and in response to tissue injury. They also reported that COX-2 enzyme was found to be strongly expressed in macrophages and myofibroblasts exclusively localized between granulation tissues of and around ulcer bed20. The expression of COX-2 enzyme in these cells is of great importance as myofibro- 
blast infiltration into the ulcer base may promote cell proliferation, differentiation or production of extracellular matrix which are required for wound healing 21 .

In the current study, it was found that treatment of duodenal ulcer with either melatonin, omeprazole or both was duration dependent. These findings could be explained by 22 who explained the mechanism of the formation of the granulation tissue. They stated that capillary endothelial cells proliferate and grow into the area to be repaired and at the same time fibroblasts are stimulated to divide and to secrete collagen and other matrix components. These modified cells are called myofibroblasts and their combination with the capillary loops is the granulation tissue.

The current results revealed that melatonin has a role in the healing of duodenal ulcer either alone or in combination with omeprazole. This result was in agreement with4 who stated that melatonin, dose-dependently, prevented gastric damage and when compared with already marketed anti-ulcer drugs such as ranitidine and omeprazole, melatonin was found to be more effective than ranitidine but less effective than omeprazole in preventing stress ulcer. They also demonstrated that co-treatment of duodenal ulcer with melatonin at low dose synergistically increases the efficacy of ranitidine and omeprazole in preventing stress induced duodenal lesion. This may be important as giving ranitidine and omeprazole at lower doses would reduce the severity of their side effects.

Another study done by ${ }^{23}$ demonstrated the presence of melatonin receptors by autoradiography and/or radioreceptor assay in the peripheral tissues including the intestinal villi. Melatonin also has been immunohistochemically demonstrated in the intestinal villi and the glandular portion of the gastro-duodenal wall. This was confirmed by 24 as they reported that melatonin is present in the gastro-intestinal tract from the stomach to the colon and it is localized and synthesized in the enterochromaffin cells of the mucosal lining. They concluded that its functions in the gut seems to be protection of the mucosa from erosion and ulcer formation and to influence the movement of

MANSOURA MEDICAL JOURNAL 
the gastrointestinal content through the digestive system.

Melatonin can exert its effect in the protection and treatment of gastro duodenal ulcer by different mechanisms. The first is the involvement of melatonin in the stimulation of the mucosa - protective alkaline secretion by duodenal mucosa 25 . It was stated by 26 that melatonin influences bicarbonate secretion in the stomach and duodenum and has a role in preventing and repairing ulcers in them. They also reported that melatonin action in the control of bicarbonate secretion involves the central and peripheral sympathetic nervous systems and this action is receptor mediated.

Another mechanism of melatonin action was presented by 27 as they found that the gastro-protecive effect of melatonin involves gastric hyperemia and this circulatory effect could be mediated either by melatonin itself or by a potent vasodilator such as PGE2 generated by the gastric mucosa. It was reported that melatonin exhibits high protective action against the damage of the gastroduodenal mucosa as it accelerates the healing of chronic peptic ulcera- tion by stimulating the microcirculation 28 .

Previous study by ${ }^{29}$ reported that the gastroduodenal protective effect of melatonin was accompanied by notable increase in plasma gastrin level suggesting that endogenous gastrin might contribute to the gastroduodenal protection afford by this in dole against stress ulcer genesis or to the acceleration of peptic ulcer healing .

Another explanation by which melatonin exerts a role in the protection and treatment of duodenal ulcer is due to its antioxidant and free radical scavenging activity as melatonin action in reducing ulcer formation involves the ability of the in dole to directly scavenge toxic oxygen based reactant as hydroxyl radical and possibly to promote the antioxidant enzyme activity 26 .

The results of this study revealed that omeprazole alone is better used in treatment of duodenal ulcer than melatonin alone as the healing of the duodenal ulcer started at the fourth week of treatment with omeprazole and was completed at the sixth week but with melatonin alone the healing

Vol. 43, No. 1 \& 2 Jan. \& April, 2014 
started at the sixth week and was healing mechanism. They also demcompleted at the eighth week of onstrated that omeprazole has signiftreatment. It was found that melato- icantly elevated the expression level nin accelerates the process of healing when combined with omeprazole as healing in combination therapy was completed at shorter duration (at the fourth week). These results were in agreement with 30 . It was reported by 3 that melatonin when combined with other antiulcer drugs like omeprazole has a beneficial effects as it accelerates the healing effects of omeprazole and shortens the duration of treatment. Therefore melatonin reduces the side effects and increases the efficacy of omeprazole.

COX-2 expression was also markedly increased in the healing ulcer. It was detected in the inflammatory cells, surface epithelium and the lining epithelium of the crypts. This was in agreement with ${ }^{31}$ who reported that these cells readily express COX-2 and synthesize prostaglandins when exposed to mitogenic or inflammatory stimuli. A recent study by 32 demonstrated high expression level of COX-2 enzyme at the healing ulcer margins and more production of prostaglandin which is a key molecule that stimulates the ulcer of COX-2 enzyme and PGE 2 level thereby it is effective in the ulcer healing process .

In healed ulcers, COX-2 activity were markedly decreased when compared to the untreated or healing ulcer. This finding was in agreement with $^{33}$ as they found marked reduction of COX-2 expression after successful treatment of duodenal ulcer. This could be explained by decreased production of COX-2 enzyme as a result of subsided inflammatory and immune responses on complete healing.

Conclusion: From the results of the present study it could be concluded that melatonin could be used in the treatment of duodenal ulcer alone but combination therapy with omeprazole is preferable as melatonin might accelerate the healing effect of omeprazole and therefore shorten the duration of treatment and minimize its side effects. It could be also concluded that COX-2 enzyme has a role in facilitating such healing process.

MANSOURA MEDICAL JOURNAL 


\section{REFERENCES}

1. Soll, A.H. (1998): Peptic ulcer and its complications, in Feldman M, Scharschmidt $\mathrm{BF}$, Sleisenger MH (eds): Sleisenger \& Fordtran's Gastrointestinal and Liver Disease, 6th ed. WB Saunders Co, pp: 620-678.

2. Graham, D.Y., White, R.H. and Moreland, L.W. (1993): Duodenal and gastric ulcer prevention with misoprostol in arthritis patients taking NSAIDs. Ann Intern Med.,119(4):257-262.

3. Reiter ,R. J., Tan, D.X. and Manchester, L.C. (2002): Antioxidative capacity of melatonin. In: Handbook of Antioxidants,2nd ed. Cadenas E,Packer L eds,Marcel Dekker,New York,pp.565613.

4. Bandyopadhyay, D., Bandyopadhyay, A., Das, P.K. and Reiter, R.J. (2002): Melatonin protects against gastric ulceration and increases the efficacy of ranitidine and omeprazole in reducing gastric damage. $\mathrm{J}$

Pineal Res. ,33(1):1-7.

5. Bruce, T.V., and Tahboub, M.R. (2002): Proton Pump Inhibitors: An Update. American Family Physician.,66(2): 273-280.

6. Lajoie, S., Sirois, J. and Doré, M. (2002): Induction of Cyclo-oxygenase-2 Expression in Naturally Occurring Gastric Ulcers. The Journal of Histochemistry \& Cytochemistry., 50(7): 923-933.

7. Cryer, B. (1998): Nonsteroidal anti-inflammatory drugs and gastrointestinal disease. In: Feldman, M. ; Scharschmidt, BF.; Sleisenger, $\mathrm{MH}$, eds.; Sleisenger and fordtran's gastrointestinal and liver disease, 6th ed. Philadelphia: Saunders, 53:343-57.

8. Jackson, L.M., Wu, K.C., Mahida, Y.R., Jenkins, D. and Hawkey, C.J. (2000): Cyclo-oxygenase (COX) 1 and 2 in normal, inflammed and ulcerated human gastric 
mucosa.Gut.,47:762 -770.

9. Araki, H., Komoike,Y., Matsumoto, M., Tanaka, A. and Takeuchi, K.(2002): Healing of duodenal ulcer is not impaired by indomethacin or rofecoxib, the selective COX-2 inhibitor, in rats. Digestion,.66(3):145-153.

10. Sung, J.J., Leung, W.K., Go, M.Y., To, K.F., Cheng, A.S., Ng, E.K., and Chan, F.K. (2000): Cyclooxygenase-2 expression in Helicobacter pylori associated premalignant and malignant gastric lesions. Am J Pathol., 157 : 729-735.

11. Paget, G.E. and Barnes, J.M. (1964): Toxicity studies. In Lawrences,D.R. and Bacharach,A.L. 2nd ed. Evaluation of drug activities:Pharmacometrics. New York:Academic press.,1155.

12. Neville, D., Yeomans, M.D., Razc, I., john, M. and Van, C.J. (2006): A comparison of omeprazole with ranitidine for ulcers associated with nonsteroidal antiinflammatory drugs. The new England Journal of Medicine.,338(11):719-726.

13. Drury, R.A.B. and Wallington, E.A. (1980): Carlton Histological Techniques. 5th ed., Oxford University Press., England. pp: 140-142.

14. Bancroft, J.D. and Gamble, M. (2002): Theory and Practice of histological techniques. 5th ed, Churchill Livingstone, New York, Philadelphia, St Louis and Toronto.pp: 171173.

15. Van Nordeen, S. (1990): Principles of immunostaining. In: Histochemistry in pathology. Filipe, M. and Lake, B. 2nd ed., Churchill Livingstone, Edinburgh, London, Melbourne and New York. pp: 31.

16. Ross, M.H., Kaye, G.K. and Pawlino, W. (2003): The MANSOURA MEDICAL JOURNAL 
EFFECT OF MELATONIN AND OMEPRAZOLE etc...

small intestine. In : Histolo-

gy. A Text and Atlas 4th ed. Lippincott Williams and Witkins, London, Hong Kong, Sydney and Tokyo, PP 491-503.

17. Stevens, A. and Lowe, J.S. (2005): Alimentary Tract. In: Human histology.3rd ed. EISevier Mosby, Philladylphia. pp:214-218.

18. Stevens, A. and Lowe, J.S. (2000): Cell injury and Death. In Pathology. 2nd ed. : Ediked by Stevens. A and Lowe. J. Mosby, An in print of Harcourt publishes limited p. 23-59.

19. Dixon, M.F. (2004): Alimentary system. In General and Systematic Pathology. 4th ed. Edited by Underwood J. C. E. Churchill Livingstone. Elsevier limited. pp: 372-375.

20. Konturek, S.J., Konturek, P.C and Brzozowski, T. (2005): Prostaglandins and ulcer healing. J Physiol Pharmacol.,56(5):5-31.
21. Kato, K., Asai, S., Murai, I., Nagata, T., Takahashi, Y., Komuro, S., Iwasaki, A., Ishikawa, K.. and Arakawa, Y. (2001): Gastroprotective and antistress roles involve both central and peripheral effects. $J$ Gastroenterol.,36(2):91-5.

22. Reiter, R.J., Tan, D.X., Mayo, J.C., Sainz, R.M., Leon, M. and Bandyopadhyay, D. (2003): Neurally - mediated and neurallyindependent beneficial actions of melatonin in the gastrointestinal tract. $\mathrm{J}$ Physiol Pharmacol., 54 (4):113-25.

23. Sjoblom, M. and Flemstrom, G. (2001): Central nervous stimuli increase duodenal bicarbonate secretion by release of mucosal melatonin. J Physiol Pharmacol.,52(4 Pt 1):671-8.

24. Brzozowska, I.., Konturek, P.C., Brzozowski, T., Konturek, S.J., Kwiecien, S., Pajdo, R., Drozdowicz, D., Pawlik, M., Ptak, A. and 
Hahn, E.G. (2002): Role of prostaglandins, nitric oxide, sensory nerves and gastrin in acceleration of ulcer healing by melatonin and its precursor, L-tryptophan. J Pineal Res.,32(3):149162.

25. Jaworek, J., Brzozowski, T.and Konturek, S.J. (2005): Melatonin as an organoprotector in the stomach and the pancreas. J Pineal Res. 38 (2):73-83.

26. Brzozowski, I., and Konturek, S.J. (1999): Acceleration of ulcer healing by cholecystokinin (CCK) ;role of CCKreceptors, somatostatin, nitric oxide and sensory nerves. Reg Pept., 82: 1933.

27. Sener-Muratoglu, G., Paskaloglu, K., Arbak, S., Hurdag, C., and AyanogluDulger, G. (2001): Protective effect of famotidine, omeprazole, and melatonin against acetylsalicylic acidinduced gastric damage in rats. Dig Dis Sci., 46(2) :318-30.

28. Lim, H.Y., Joo, H.J., Choi, J.H., Yi, J.W., Yang, M.S., Cho, D.Y., Kim, H.S., Nam, D.K., Lee, K.B. and Kim, H.C. (2000): Increased expression of cyclooxygenase- 2 protein in human gastric carcinoma. Clin Cancer Res., 6:519-525.

29. Tatsuguchi, A., Sakamoto, C., Wada, K., Akamatsu, T., Tsukui, T.,Miyake,K., Futagami, S., Kishida, T., Fukuda, Y., Yamanaka, N. and Kobayashi, M. (2005): Localisation of cyclo-oxygenase 1 and cyclo-oxygenase 2 in Helicobacter pylori related gastritis and gastric ulcer tissues in humans. Gut., 46 : 782-789.

30. Hull, M.A, Brough, J.L. and Hawkey, C.J. (1999): Expression of cyclooxygenase- 1 and -2 by human gastric endothelial cells. Gut., 45:529.

MANSOURA MEDICAL JOURNAL 
31. Wu, K.C., Jackson, L.M., and Galvin, A.M. (1999): Phenotypic and functional characterization of myofibroblasts, macrophages, and lymphocytes migrating out of the human gastric lamina propria following the loss of epithelial cells. Gut., 44(3):323-330.

32. Poonam, D., Vinay, C.S. and Gautam, P. (2005): Cyclooxygenase-2 expression and prostaglandin E2 production in experimental chronic gastric ulcer healing. Eur J Pharmacol.; 20; 519(3):277-84.

33. Wallace, J.L., McKnight, W. and Reuter, B.K. (2000): NSAID-induced gastric damage in rats: requirement for inhibition of both cyclooxygenase 1 and 2 . Gastroenterology., $\quad 119$ : 706-14. 


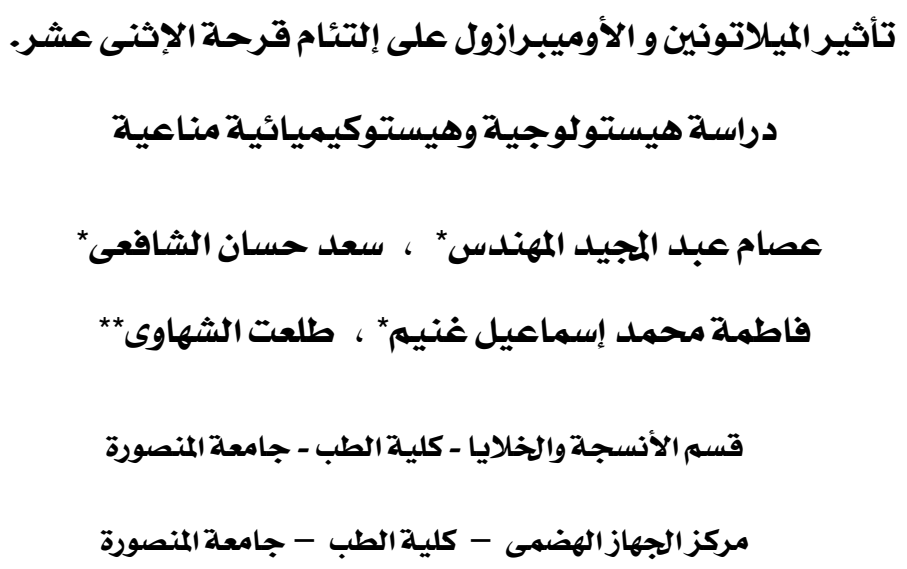

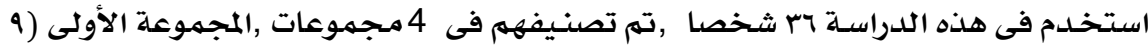
متطوعين كمجموعة ضـايطة) المجموعة الثانية (9 مـرضى يعانون من قرحة الإثنى عشر ويعالجون

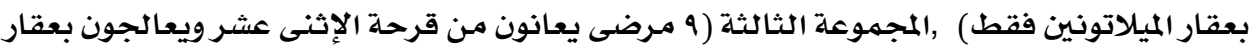

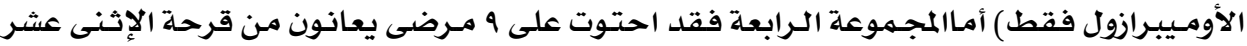

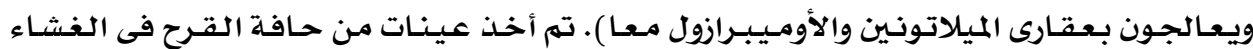
المخاطى عن طريق المنظار وعولجت لإجراء دراسـة هيستولوجية وهيستوكيميائية مناعيلة.

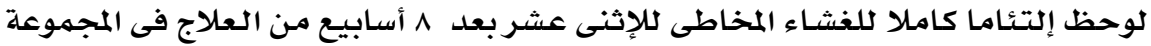

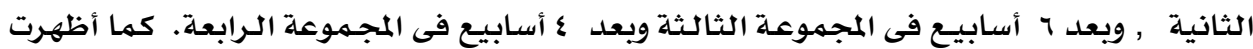

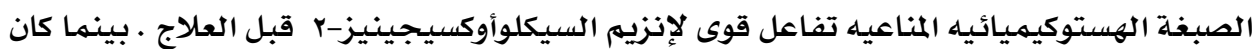

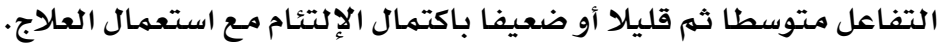

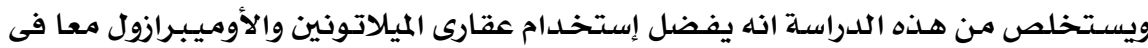

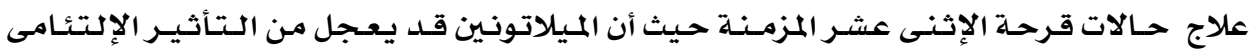

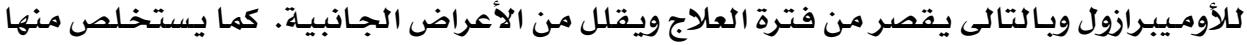

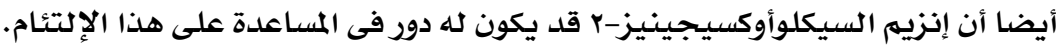

